\title{
Predictive microbiology: Modeling microbial responses in food
}

\author{
Md. Fakruddin ${ }^{1 *}$, Reaz Mohammad Mazumder² and Khanjada Shahnewaj Bin Mannan ${ }^{3}$ \\ ${ }^{1}$ Institute of Food Science and Technology (IFST), Bangladesh Council of Scientific and Industrial \\ Research (BCSIR), Dhaka, Bangladesh. \\ ${ }^{2}$ BCSIR Laboratories Chittagong, Bangladesh Council of Scientific and Industrial Research (BCSIR), \\ Bangladesh. \\ ${ }^{3}$ Enteric \& Food Microbiology Laboratory, Laboratory Sciences Division, ICDDR, B. Dhaka, Bangladesh. \\ Accepted 02 November 2011
}

\begin{abstract}
Predictive microbiology is the integration of traditional microbiology knowledge with those found in the disciplines of mathematics, statistics and information systems and technology to describe microbial behaviour in order to prevent food spoilage as well as food-borne illnesses. The behaviour of microbial populations in foods (growth, survival, or death) is determined by the properties of food (e.g., water activity and $\mathrm{pH}$ ) and the storage conditions (e.g., temperature, relative humidity, and atmosphere). The effect of these properties can be predicted by mathematical models derived from quantitative studies on microbial populations. Using predictive models changes in microbial populations in foods from production/ harvest to consumption can be estimated from changes in product parameters (temperature, storage atmosphere, $\mathrm{pH}$, salt /water activity, etc.). Predictive microbiology models have immediate practical applications to improve microbial food safety, quality, and are leading to the development of a quantitative understanding of the microbial ecology of foods. While models are very useful decisionsupport tools it must be remembered that models are, at best, only a simplified representation of reality. Because of the complexity of microbial behaviour and food systems, predictive microbiology presents some limitations. Predictive microbiology provides a powerful tool to aid the exposure assessment phase of 'quantitative microbial risk assessment' and it can be concluded that predictive models, successfully validated in agreement with defined performance criteria, will continue to be an essential element of exposure assessment within formal quantitative risk assessment.
\end{abstract}

Keywords: validation, applications, limitations

\section{INTRODUCTION}

An area of food microbiology has come to be known as "predictive microbiology" in the last few decades. In the first book on the subject, published just over 20 years ago, McMeekin et al. (1993) defined it as a quantitative science that enables users to evaluate objectively the effect of processing, distribution and storage operations on the microbiological safety and quality of foods. The goal of predictive microbiology is to develop mathematical equations that describe the behaviour of microorganisms under different environmental factors (physical, chemical, competitive). Predictive modeling of bacterial growth and inactivation is an important research topic among food microbiologists (Buchanan, 1993, Skinner and Larkin, 1994, McMeekin et al. 1997). Predictive models allow to estimate the shelf-life of foods, isolate critical points in the production and distribution process and can give insight on how environmental variables affect the behaviour of pathogenic or spoilage bacteria. Predictive microbiology provides us with an estimate of the potential growth of particular microorganisms under a variety of conditions. The models used in predictive microbiology are developed from experimental work, usually conducted in laboratory media. These models are then extrapolated to foods.

\section{Predictive microbiology}

Predictive microbiology may be considered as the application of research concerned with the quantitative microbial ecology of foods. The subject is based on the premise that the responses of populations of microorganisms to environmental factors are reproducible and that, by characterizing environments in terms of these factors (affecting microbial growth and survival most), it is possible from past observation to predict the responses of microorganisms in other similar environments. The term "quantitative microbial ecology" has been suggested as an

*Corresponding author's email: fakruddinmurad@gmail.com 
alternative to "predictive microbiology" (Ross and McMeekin, 1995).

The concept of predictive microbiology is new in its application and not in its existence. Esty and Meyer (1922) had used mathematics to determine the survival of microorganisms. Modeling microbial growth was also being done in the field of industrial microbiology (Monod, 1949). However, it has been recognized that food microbiology should build its own repository of models without copying those used in industrial microbiology, as their objectives are different (Baranyi and Roberts, 1994).

Predictive microbiology deals with knowledge of microbial growth responses to environmental factors summarized as equations or mathematical models. A database may be formulated to store raw data and models from which the information can be retrieved and this information can be used to interpret the effect of processing and transportation practices on microbial proliferation (McMeekin et al., 1997). Coupled with information on environmental history during processing and storage, predictive microbiology provides support in making decisions on the microbiologic safety and quality of foods.

The development, validation, and application of predictive microbiology has been extensively reviewed in the last few decades (McMeekin, 1993; Whiting et al., 1997). Early modeling studies mostly concerned on thermal inactivation of pathogenic bacteria (Munoz-Cuevas et al., 2011), but later modeling studies have concentrated on descriptions of the effect of constraints on microbial growth (rather than survival or death), often using a kinetic model approach (rather than probability modeling) and most often describing the effect of temperature as the sole or one of a number of controlling factors. For example, the temperature dependence model for growth of Clostridium botulinum demonstrated a good fit to data, but the authors noted that "care must be taken at extremes of growth, as no growth may be registered in a situation where growth is indeed possible but has a low probability" (Graham and Lund, 1993).

\section{History}

The development of log-linear microbial death kinetics by Bigelow et al., (1920), Bigelow (1921) and Esty and Meyer (1922) was the first example of a predictive model to find widespread application in the food industry. Roberts and Jarvis (1983) were the first to coin the term 'Predictive Microbiology' (Brul, 2007).
Predictive microbiology started as a purely empirical (though quantitative) science. Its earliest appearance is probably Esty and Meyer (1922), who described the thermal death of Clostridium botulinum type A spores by a loglinear model, which is still used to estimate the necessary heat processing in low-acid canned foods. This model simply says that, at a given temperature, the relative (or specific) death rate of the bacteria is constant with time. In other words, the percentage of the cell population inactivated in a unit time is constant. This is a simple, logical and understandable model, similar to those commonly used in physical and chemical sciences for processes such as dissipation, diffusion, etc, when the force that causes the decrease of a certain quantity is constant with time (Baranyi and Roberts, 2004).

A step forward was taken by Scott (1936), who investigated how the specific death rate depended on the available water, quantified today by the so-called water activity, a dimensionless number between 0 (dry) and 1 (wet). He subsequently studied the specific effect of temperature on the microbial death rate. Today the most frequently assumed relation in thermal inactivation theory is that the logarithm of the specific death rate decreases linearly as the temperature increases (this is equivalent to the so-called constant z-value theory) (Baranyi and Roberts, 2004).

\section{Modeling bacterial growth}

Microbial modeling allows the description and prediction of microbial behaviour under specific environmental conditions. These conditions can be intrinsic, like $\mathrm{pH}$ or extrinsic, like temperature or salinity. Microbial responses are tested under controlled conditions and the results are then expressed as a mathematical equation that will allow prediction of untested combinations of conditions (Hajmeer and Cliver, 2002). Even though several conditions affect the growth or decline in microbial populations, only a few have a significant influence, and it is preferred to use as few variables as possible in the equation. It is assumed that the effect of a factor is independent of whether the microorganisms are in a broth or food, as long as other relevant factors are equivalent (Ross and McMeekin, 1994; Whiting, 1995).

\section{Types of models}

There are several ways to classify models. Models can be classified, by the microbiological event into kinetic and probability models (Roberts, 1989); the modeling approach used into Empirical and Mechanistic ways (Roels and 
Kossen, 1978); or by the variables considered into primary, secondary and tertiary (Whiting and Buchanan, 1993).

\section{Kinetic and probability models}

Kinetic models are considered with the rates of response (Growth or death). Examples include the Gompertz and square root models which, describe the rates of response, like lag time, specific growth rate and maximum population density (McMeekin et al., 1993; Whiting and Buchanan 1994) or inactivation/ survival models that describe destruction or survival over time (Xiong et al., 1999b).

Probability models, originally used for predicting the likelihood that organisms grow and produce toxin within a given period of time (Hauschild, 1982; Stumbo et al., 1983), have been more recently extended to define the absolute limits for growth of microorganisms in specified environments e.g. in the presence of a number of stresses which individually would not be growth limiting, but collectively prevent growth (Baker and Genigeorgis, 1990). Probability models indicate only the probability of growth or toxin production and do not indicate the speed at which they occur (Roberts, 1989).

\section{Empirical and mechanistic models}

Empirical models usually take the form of first or second degree polynomials and are essentially pragmatic describing the data in convenient mathematical relationship (curve fitting). An example is the quadratic response surface used by Gibson et al. (1988). Mechanistic or deterministic models are built up from theoretical bases and allow interpretation of the response in terms of known phenomena and processes. Attempts, like those of McMeekin et al. (1993), to find a fundamental basis for the square root model are important steps towards more mechanistic approaches. Draper (1988) considers the mechanistic models to be more preferable than the empirical ones, as they usually contain fewer parameters, fit the data better and extrapolate more sensibly.

Whiting and Buchanan (1993) have proposed a three level classification method described as primary, secondary and tertiary.

\section{Primary models}

These models measure the response of the microorganism with time to a single set of conditions. The response can either be direct / indirect measures of microbial population density or products of microbial metabolism. These primary models include growth models (Gibson et al. 1987; Buchanan et al. 1989), the growth decline model (Whiting and Cyhnarowicz 1992), D-values or thermal inactivation (Rodriguez et al. 1988), inactivation/ survival models (Kamau et al. 1990, Whiting, 1992), growth rate values (McMeekin et al., 1987) and even subjective estimation of lag time or times to turbidity/ toxin formation (Baker et al. 1990). Some of the examples of primary models are given in Fig. 1.

$$
\begin{array}{lc}
\text { Exponential model } & \log \left(N_{t}\right)=\log \left[N_{0} \times \exp \left(\mu_{\max } \times \text { time }\right)\right] \\
\text { Logistic model } & \log \left(N_{t}\right)=\log \left(\frac{N_{\max }}{1+\left[\frac{N_{\max }}{N_{0}}-1\right] \times \exp \left(-\mu_{\max } \times \text { time }\right)}\right) \\
\text { without lag } & \log \left(N_{t}\right)=\log \left(N_{\min }+\frac{N_{\max }-N_{\min }}{1+\exp \left(-\mu_{\max }\left(t i m e-t_{i}\right)\right)}\right) \\
\text { Logistic model } &
\end{array}
$$

\footnotetext{
Baranyi \& Roberts (1994)

$\log \left(N_{t}\right)=\log \left(N_{0}\right)+\frac{1}{\mu_{\max }} \times\left[\operatorname{time}+\frac{1}{\mu_{\max }} \times \operatorname{Ln}\left(\frac{\exp \left(-\mu_{\max } \times \operatorname{time}\right)+q_{0}}{1+q_{0}}\right)\right]-\frac{1}{\log (10)} \times \operatorname{Ln}\left(1+\frac{\exp \left(\mu_{\max } \times\left[\operatorname{time}+\frac{1}{\mu_{\max }} \times \operatorname{Ln}\left(\frac{\exp \left(-\mu_{\max } \times \text { time }\right)+q_{0}}{1+q_{0}}\right)\right]\right)-1}{\exp \left(\log \left(N_{\max }\right)-\log \left(N_{0}\right)\right)}\right)$

Modified Gompertz $\log \left(N_{t}\right)=\log \left(N_{0}\right)+\left(A \times \exp \left(-\exp \left[\frac{\mu_{\max } \times \exp (1)}{A} \times(\operatorname{lag}-\right.\right.\right.$ time $\left.\left.)+1\right]\right) / \operatorname{Ln}(10)$
model
}

Figure 1. Some primary models that measure the response of microorganisms.

(Source: McKellar and Lu, 2004) 


\section{Development of predictive microbial models}

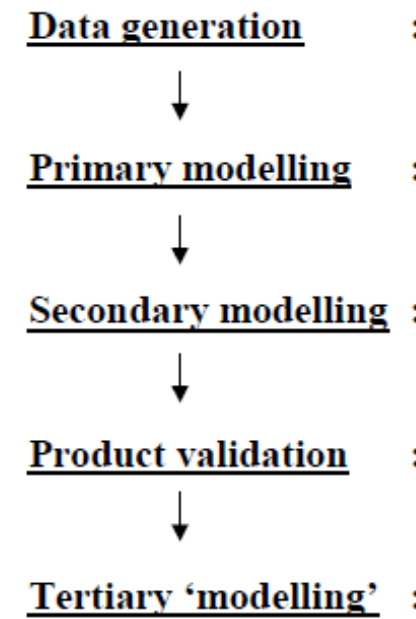

Growth curves are generated in model systems for combinations of environmental factors (temp., $\mathrm{pH}, \mathrm{NaCl}$, etc.)

Growth curves are fitted by sigmoidal growth models

The effect of controlling factor(s) on kinetic parameters (e.g. the lag phase and the growth rate) is modelled

Predicted values of kinetic parameters are compared to values obtained in products and challenge tests

Validated models are included in application software

Figure 2. Development of predictive models in microbiology.

\section{Secondary models}

These models indicate how parameters of primary models change with respect to one or more environmental or cultural factors (e.g. atmosphere, $\mathrm{pH}$, temperature and salt level). Response surface (Buchanan and Philips 1990), Arrhenius (Broughall et al., 1983), Belehradek (Ratkowsky et al., 1991), secondary models based on gamma concept such as those described by Rosso et al. (1995) are some examples of this type of models. Secondary models may be further categorized as direct or indirect.

\section{Tertiary models}

These are applications of one or more secondary models to generate systems for providing predictions to non-modelers, i.e. user-friendly or applications software (Buchanan, 1991; Buchanan, 1993) and expert systems (Adair et al., 1993). This level would include algorithms to calculate changing conditions (e.g. transient temperature after 5 days of storage) on the growth and survivality of microorganisms, compare microbial behaviour under different conditions (two salt levels), or graph the growth of several microorganisms simultaneously (Buchanan, 1991).

\section{Development of models}

Basic procedure for development of a model is shown in Fig. 2.

\section{Validation of models}

To assess the reliability of models before they are used to aid decisions, they (models) have to be validated. Two steps must be taken to validate a model once it has been built.

The first is to test its accuracy with new data and new combinations of variables to determine if the model can describe the experimental data sufficiently. This is called internal validation, also termed 'Curve fitting'. This will allow an estimation of the goodness of fit and will show if and where additional data is needed. Complex models tend to be very specific, which can be a limitation when testing new data.

The second step is to compare model predictions with microbial responses in actual foods. This is called External Validation. This will show the model's limitations and may show if additional factors must be tested and included in the model. Errors in growth or survival should always tend towards faster growth rates or better survival, respectively, to make a conservative prediction (Whiting, 1995).

Models cannot be used with confidence, until this validation is done. Growth rates or Statistical measures like Root Mean-square Error (RMSE) and regression coefficient or coefficient of determination $\left(\mathrm{r}^{2}\right)$ values were used by Duh and Schaffner (1993) to assess the reliability of predictive equations developed based on measurements in brain heart infusion broth and those of literature values in food. These terms 
have been used to mathematically compare data derived from literature (Giffel and Zwietering, 1999). McClure et al. (1993) compared their models on the basis of the sum of the squares of the differences of the natural logarithm of observed and predicted values and suggested that a smaller value indicates a model, which, on average, better predicts the observed response. Two important factors for validation of predictive models are accuracy factor and bias factor introduced by Ross (1996). Accuracy and bias factors are the mean square differences between predictions and observations (Baranyi et al._1999).

\section{Limitations of model}

There are some limitations of predictive microbiology that need to be considered. They are:

The models cannot be extrapolated outside the ranges (e.g. $\mathrm{T}^{\circ} \mathrm{C}, \mathrm{a}_{\mathrm{w}}$ ) in which they were derived. This is because the models are derived from fitting the observed data and therefore do not model microbial behaviour. Predictions outside the experimental ranges are usually not accurate and in some cases are nonsensical.

The models usually predict faster growth rates than are observed. This makes them failsafe but they may be overly conservative. The reason for this is the models are usually conducted in laboratory media and while they are validated in foods, they may not have widespread application in the food industry.

Several workers have also pointed out that models derived in static conditions may not be applicable to fluctuating conditions i.e. those in which environmental conditions like temperature, $\mathrm{pH}$, gaseous atmosphere and water activity change during the life of the product (Mackey and Kerridge, 1988; Gibbs and Williams, 1990).

Previous incubation conditions of the test organisms can affect the subsequent rate of growth of organisms (Walker, 1990; Fu et al., 1991; Buchanan and Klawitter, 1991). Fu et al. (1991) termed this a "Temperature history effect" and other environmental conditions like $\mathrm{pH}$ have also been investigated under this "history effect".

Therefore, great caution is required in the use of microbial models as scepticism exists that models derived in an experimental system can reliably predict the growth of the modeled organism in a food and It is very important that the model is accompanied by a description of its limitations; specific microorganisms, factors tested and considered in the model, ranges for each of these factors, and combinations of factors. The model user must be aware that using the model outside its limitations may not give valid answers.

\section{Applications of predictive microbiology}

Some of the applications of predictive microbiology are listed in Table 1.

\section{Predictive microbiology and HACCP}

HACCP is a system to identify and prevent the potential food safety problems with the manufacture, distribution and use of a food product. The system attempts to identify the pathogens in raw materials, routes for entry of pathogens into the processing environment, the methods for their elimination, and potential problems with the finished product when not handled properly. A comparison of HACCP and predictive microbiology is given in Table 2 .

Thus predictive food microbiology can be viewed as an extension of the HACCP concept. Hence, the HACCP concept and its integration with predictive models have great potential as decision-making tools. They help in establishing critical limits and in the disposition of a product that deviates from the established critical limits. A critical control point can exist where the model indicates that a certain level of a factor permits or surpasses microbial growth. Quantifiable estimates of microbial behaviour at different levels of the factors can suggest the allowable ranges for that factor. The potential for predictive microbiology to offer decision support and aid in process optimization is the subject of extensive research worldwide (Vose, 1998; McNab, 1998).

\section{Current status of predictive microbiology}

Over the years, researchers have pointed out and discussed problems with predictive microbiology and many of them suggested needed research. Efficacy of models to predict outcomes under real life conditions are still contradictory. Models developed in laboratory broth systems have been reported to be inappropriate to describe growth on food (Gill et al., 1997). Dalgaard (1995) suggested an iterative approach to model development using food, rather than laboratory media, as the growth substrate for model development. Models should be validated rigorously under practical conditions. 
Table 1. Applications of predictive microbiology.

\begin{tabular}{|c|c|}
\hline Area of Application & Example \\
\hline Hazard Analysis Critical Control & Preliminary hazard analysis \\
\hline Point (HACCP) & $\begin{array}{l}\text { Identification and establishment of critical control } \\
\text { point(s) } \\
\text { Corrective actions } \\
\text { Assessment of importance of interaction between } \\
\text { variables }\end{array}$ \\
\hline Risk assessment & $\begin{array}{l}\text { Estimation of changes in microbial numbers in a } \\
\text { production chain } \\
\text { Assessment of exposure to a particular pathogen }\end{array}$ \\
\hline Microbial Shelf life studies & $\begin{array}{l}\text { Prediction of the growth of specific food spoilers } \\
\text { Prediction of growth of specific food pathogens }\end{array}$ \\
\hline Product research and development & $\begin{array}{l}\text { Effect of altering product composition on food safety } \\
\text { and spoilage } \\
\text { Effect of processing on food safety and spoilage } \\
\text { Evaluation of effect of out-of-specification } \\
\text { circumstances }\end{array}$ \\
\hline $\begin{array}{l}\text { Temperature function integration and } \\
\text { hygiene regulatory activity } \\
\text { Education } \\
\text { Design of experiments }\end{array}$ & $\begin{array}{l}\text { Consequence of temperature in the cold chain for } \\
\text { safety and spoilage } \\
\text { Education on safety, especially non-technical people } \\
\text { Number of samples to be prepared } \\
\text { Defining the interval between sampling }\end{array}$ \\
\hline
\end{tabular}

Table 2. Comparison of HACCP and predictive microbiology.

HACCP
Identify potential hazards and assess their severity
at different stages of processing or operations.
Identify the Critical Control Points (CCP)
where control measures need to be
implemented.
Specification of control criteria and methods to
ensure a control has been achieved (when
necessary).

\section{Predictive Microbiology}

Identify the microorganism(s) of concern

Develop an understanding of the ecology of microorganism to better identify the source and the likelihood of contamination.

Compare information with preset control specifications (i.e., accept/reject criteria)
Establish and implement monitoring procedures, and response measures to noncompliance situations.
Incorporate the available information into monitoring systems that indicate microbial proliferation
In real conditions, situations may deviate from the predictions of models but this type of deviations does not necessarily imply that the model is defective. Rather it implies that knowledge of some food ecosystems is incomplete and factors other than those used in model development have an effect on microbial behaviour.

The common theme of the problems in predictive microbiology discussed above is that of uncertainty-uncertainty in terms of the starting conditions (e.g., initial microbial load and types) and the microbial response in a static or changing environment. Uncertainty translates to variability if the distribution of response times is understood and the variance can be described. As we have indicated above, the variability associated with very long response times limits the utility of kinetic models and requires a probability approach. Thus, while in the last few decades predictive modelers were justified in their selection of temperature as a primary factor to model in kinetic approaches, the next decade may see a return to probability modeling as 
pioneered by Genigeorgis (1981) and Roberts et al. (1981). This shift will derive impetus from the emergence of dangerous pathogens with very low infective doses, and continued kinetic modeling will concentrate on survival and death rather than growth of populations.

The first kinetic death model to find widespread use in the food industry was for thermal destruction (Stumbo et al., 1983). As an example of such model, we can consider a model describing a 12-log cycle reduction of Clostridium botulinum spores in a short time with considerable certainty. Current research is approaching toward less severe processes with longer response times and to the complications of "shoulders" and "tails" to define the growth/no growth interface. Biologic variability will again dictate a probability approach to describe the survival and slow decline of microbial populations (McMeekin et al., 1997).

\section{Challenges in predictive microbiology}

Considerable progress has been made in defining philosophic approaches and experimental protocols for growth model development and many models have been developed and published, as a result more validation studies are required, particularly involving independent and industry based trials. More emphasis should be placed on modeling the death kinetics of foodborne pathogens with low infective doses. Measurement of environmental factors (e.g. temperature) can be achieved with precision, but in some situations, (e.g. in chilling of meat carcasses), it is more difficult (McMeekin et al., 1997). Location of the sensor can be an important consideration (Gill et al., 1991a, Gill et al., 1991b). Furthermore, development of techniques to measure constraints such as water activity, $\mathrm{pH}$, or redox potential on a microscale might provide useful information for a complex food such as salami. This would allow definition of the role of the microenvironment in determining microbial behaviour (McMeekin et al., 1997).

The inherent variability of response times (generation time and lag phase duration) is an issue in predictive microbiology (Ratkowsky et al., 1996). The variance was shown to be proportional to the square or cube of the response time (Ratkowsky, 1991; Alber and Schaffner, 1992; Ratkowsky et al., 1996c). The practical implication of these findings for the application of kinetic models is that inherent biologic variability increases markedly with increasing response times, and thus the confidence limits associated with predictions also increase markedly. However, if the probability distribution of the response time is known, one can determine the probability that an organism will grow more quickly than a predicted response time (Ratkowsky et al., 1996c). Thus, kinetic models are appropriate to describe consistent microbial growth responses, but under extreme conditions a probability approach may be required (McMeekin et al,. 1997)

Models must be validated in foods under conditions that mimic situations encountered in normal practice, e.g., decreasing temperature and water activity during active chilling of meat carcasses or fluctuating temperatures during the distribution and storage of many food commodities (McMeekin et al., 1997).

Modeling lag phase duration is also a problem (Baranyi et al., 1995). Predicting lag phase duration in foods is very difficult not due to the lack of a suitable model, rather the difficulty comes from the lack of knowledge of the physiologic status of the microorganisms contaminating the food. The organisms may include cells that are actively growing, exhibiting a physiologic lag phase, damaged and under repair, exhibiting physiologic (endospores) or exogenous dormancy (VNC cells), damaged but unable to reproduce because of ineffective repair mechanisms, and dead (McMeekin et al., 1997).

Methods to define the physiologic status of food-borne contaminants under various conditions need to be developed. This will require observations on individual cells or small populations of cells either directly by microscopy or an indicator of single-cell metabolic activity (Baranyi and Roberts, 1995). Luminescent Salmonella strains have been used as real-time reporters of growth and recovery from sub-lethal injury (Chen and Griffiths, 1996). Alternatively, a parameter to describe the suitability of cells to grow in a new environment may be incorporated in the model (Baranyi and Roberts, 1995).

\section{Future prospect}

Models should be developed which take into consideration possible interactions between microbial flora present in the product (Griffiths, 1994; Ross and McMeekin, 1994). This is especially true of dairy products where lactic acid bacteria, preservatives used in foods, synergistic effects between organisms have a profound influence on microbial growth and these require consideration in future model development.

Mathematical modelling of fungal growth has not received a similar degree of interest as 
modelling of bacterial growth and there is a need for concerted effort from scientists, food manufacturers and processors to overcome the hurdles faced in modelling fungal growth in foods (Gibson and Hocking, 1997). Spoilage organisms have also not received much attention for development of comprehensive models (Whiting, 1997). Other microbial situations that need microbial modeling are growth in heterogeneous foods, on surfaces or boundaries, in microenvironments and biofilms (Whiting, 1997).

Progress is expected in the area of:

Dynamic modeling: interaction between bacteria and environmental factors

Lag modeling: by means of quantifying and modeling the effect of history via the actual physiological state of the bacteria

Growth / no growth boundaries for bacteria and environment

Probability of growth: for answering the question "what is the probability that the microbial load is over a specified value, at a specified time?" (for Quantitative Microbial Risk Assessment purposes)

More advanced quantification of the structure of the food environment

Modeling individual cell kinetics by stochastic birth/death processes: Connecting deterministic modeling at population level to statistical assessment and variability characterization at single cell level

Relating predictive microbiology and molecular microbiology: using data on how genes are switched on as a function of the (dynamically changing) environment; characterization of variability and stress-tolerance;

Computational microbiology and bioinformatics development: data storage and retrieval in a more advanced way.

These tasks require the interdisciplinary collaboration of food microbiologists and mathematicians; food technologists and computer scientists; molecular microbiologists and statisticians.

\section{CONCLUSION}

Just 20 years ago very few food microbiologists believed that models of microbial growth and death would ever be sufficiently reliable to be used in the food industry, or by food regulators. From the early empirical models, a new generation of modeling approaches, together with international collaboration, has opened the door to the possibility of predicting growth and death properties for the key microorganisms in food. In this summary of our current predictive microbiology knowledge, readers can find a comprehensive picture of the direction the subject is expected to continue and what is likely to change.

\section{ACKNOWLEDGEMENTS}

The authors are indebted to Mr. Monzur Morshed Ahmed, Senior Scientific Officer, Institute of Food Science and Technology (IFST), Bangladesh Council of Scientific and Industrial Research (BCSIR) for introducing us to the exciting field of Predictive Microbiology.

\section{REFERENCES}

Adair, C. and Briggs, P.A. (1993). The concept and application of expert systems in the field of microbiological safety. J. Ind. Microbiol. 12: 263-267.

Alber, S. A. and Schaffner, D.W. (1992). Evaluation of data transformations used with the square root and Schoolfield models for predicting bacterial growth rate. Appl. Environ. Microbiol. 58:3337-42.

Baker, D.A. and Genigeorgis, C (1990). Predicting the safe storage of fresh fish under modified atmospheres with respect to Clostridium botulinum toxigenesis by modelling length of lag phase of growth. $J$. Food Prot. 53: 131-140.

Baranyi, J. and Roberts T.A. (1994). A Dynamic Approach to Predicting Bacterial Growth in Food. Int.l J. of Food Microbiology 23(3-4): 277-94.

Baranyi, J., Robinson, T.P., Kaloti, A. and Mackey, B.M. (1995). Predicting growth of Brocothrix thermosphacta at changing temperature. Int. J. Food Microbiol. 27: 6175.

Baranyi, J. and Roberts, T.A. (1995). Mathematics of predictive food microbiology. Int. J. Food Microbiol. 26: 199-218.

Baranyi, J., Pin, C. and Ross, T. (1999). Validating and comparing predictive models. Int. J. of food Microbiology 48(3):159-66.

Baranyi, J. and Roberts T.A, (2004). Predictive Microbiology - Quantitative Microbial Ecology. Culture. http://www.ifr.ac.uk /safety/ comicro/Culture_25pdf

Bigelow, W.D. (1921). The Logarithmic nature of thermal death time curves. J. Infect. Dis. 29: $528-536$. 
Bigelow, W.D., Bohart, G.S., Richardson, A.C. and Ball, C.O. (1920). Heat Penetration in processing canned foods. National Canners Association Bulletin. 16-L.

Broughall, J.M., Anslow, P.A., Kilsby, D.C. (1983). Hazard analysis applied to microbial growth in foods: Development of mathematical models describing the effect of water activity. J. Appl. Bacteriol. 55: 101110.

Brul, S. (2007). Introduction of Predictive Microbiology. (Eds.) Stanley Brul, Suzanne van Gerwen, Marcel Zwietering. Modeling Microorganisms in Food. Cambridge, England, Woodhead Publishing Limited. Pp. 9.

Buchanan, R. L. and Phillips, J. G. (1990). Response surface model for predicting the effects of temperature, $\mathrm{pH}$, sodium chloride content, sodium nitrite concentration and atmosphere on the growth of Listeria monocytogenes. J. Food Protect. 53: 370-376.

Buchanan, R. L. and Klawitter, L. A. (1991). Effect of temperature history on the growth of Listeria monocytogenes at refrigeration temperatures. Int. J. Food Microbiol. 12: 235 246.

Buchanan, R.L. (1993). Predictive food microbiology. Trends Food Sci. Technol. 4: 611.

Buchanan, R.L. (1991). Using spreadsheet software for predictive microbiology applications. J. Food Saf. 11: 123-134.

Buchanan, R.L., Stahl, H.G. and Whiting, R.C. (1989). Effects and interactions of temperature, $\mathrm{pH}$, atmosphere, sodium chloride, and sodium nitrite on the growth of Listeria monocytogenes. J. Food Prot. 52: 844-851.

Chen, J. and Griffiths, M.W. (1996). Luminescent Salmonella strains as real time reporters of growth and recovery from sublethal injury in food. Int. J. Food Microbiol. 31: 27-44.

Dalgaard, P. (1995). Predictive microbiological modeling and seafood quality. In: Seafood from producer to consumer, integrated approach to quality. Proceedings of the International Seafood Conference, 1995 Noordwijkerhout. The Netherlands: Elsevier, Amsterdam.

Draper, N.R. (1988). Response surface designs. In: Encyclopedia of Statistical Sciences, Wiley, New York. Pp. 107-119.

Duh, Y. H. and Schaffner, D.W. (1993). Modeling the effect of temperature on the growth rate and lag time of Listeria innocua and Listeria monocytogenes. J. Food Prot. 56: 205-210.

Esty, J.R. and Meyer, K.F. (1922). The heat resistance of the spore of Bacillus botulinus and allied anaerobes, XI. J. Infect. Dis. 31: 650-663.

Fu, B., P. S, Taoukis, and T. P. Labuza (1991). Predictive microbiology for monitoring spoilage of dairy products with timetemperature integrators. J. Food Sci. 56: 12091215.

Genigeorgis, C.A. (1981). Factors affecting the probability of growth of pathogenic microorganisms in foods. J. Am. Vet. Med Assoc. 179:1410-7.

Genigeorgis, P.A. and Williams, A.P. (1990) In: Using Mathematics for Shelf Life Prediction, Food Technol. Int, Europe. Pp. 287-290.

Gibbs, P.A., Williams, A.P. In: Using Mathematics for Shelf Life Prediction, Food Technol. Int, Europe, pp. 287-290 (1990).

Gibson, A.M., Bratchell, N. and Roberts, T.A. (1988) Predicting microbial growth: growth responses of salmonellae in a laboratory medium as affected by $\mathrm{pH}$, sodium chloride and storage temperature. Int. J. Food Microbiol. 6: 155-178.

Gibson, A.M., Bratchell, N. and Roberts, T.A. (1987). The effect of sodium chloride and temperature on the rate and extent of growth of Clostridium botulinum type $\mathrm{A}$ in pasteurised pork slurry. J. Appl. Bacteriol. 62: 479-490.

Gibson, A.M. and Hocking, A.D. (1997) Advances in the predictive modelling of fungal growth in food. Trends Food Sci. Technol. 8: 353-358.

Giffel, M.C., Zwietering, M.H. (1999) Validation of predictive models describing the growth of Listeria monocytogenes. Int. J. Food Microbiol. 46: 135-149.

Gill, C.O., Greer, G.G. and Dilts, B, D. (1997). The aerobic growth of Aeromonas hydrophila and Listeria monocytogenes in broths and on pork. Int. J. Food Microbiol. 35:.67-74.

Gill, C.O., Harrison, J.C.L. Phillips and D.M. (1991a) Use of a temperature function integration technique to assess the hygienic efficiency of a beef carcass cooling process. Food Microbiology. 8:83-94.

Gill, C.O. Jones, S.D.M., Tong, A.K.W. (1991b). Application of a temperature function integration technique to assess the hygienic efficiency for spray chilling beef carcasses. Journal of Food Protection. 54:731-6.

Graham, A. and Lund, B.M. (1993). The effect of temperature on the growth of non 
proteolytic type B Clostridium botulinum. Letters in Applied Microbiology 16: 158- 60.

Griffiths, M.W. (1994). Predictive modeling: applications in the dairy industry. Int. J. Food Microbiol. 23: 305-315.

Hajmeer, M.N. and Cliver D.O. (2002). Microbiology of Food Preservation and Sanitation. In: Food borne Diseases. Cliver, D.O. and Riemann, H. (Eds.) Academic Press, New York, NY. Pp. 330-352.

Hauschild, A.H.W. (1982). Assessment of botulism hazards from cured meat products. Food Technol. 36: 95-104.

Kamau, D.N., Doores, S., Pruitt, K. M. (1990). Enhanced thermal destruction of Listeria monocytogenes and Staphylococcus aureus by the lactoperoxidase system. Appl. Environ. Microbiol. 56: 2711-2716.

Mackey, B. M. and Kerridge, A. L. (1988). The effect of incubation temperature and inoculum size on growth of salmonellae in minced beef. Int. J. Food Microbiol. 6: 57-65.

McClure, P.J., Baranyi, J., Boogard, E., Kelly, T.M. and Roberts, T.A. (1993). A predictive model for the combined effect of $\mathrm{pH}$, sodium chloride and storage temperature on the growth of Brochothrix thermosphacta. Int. J. Food Microbiol. 19: 161- 178.

McKellar, R. and Lu, X (Eds). (2004) Modeling Microbial responses on foods, Boca Raton, FL, CRC Press.

McMeekin, T., Brown, J. and Krist, K. (1997). Quantitative microbiology: a basis for food safety. Emerging infectious diseases 3(4): 541-9.

McMeekin, T. A., Olley, J., Ross, T. and Ratkowsky, D.A. (1993). Predictive microbiology: theory and application. Taunton, UK: Research Studies Press.

McMeekin, T.A., Chandler, R.E., Doe, P.E., Garland, C.D., Olley,J., Putro, S. and Ratkowsky, D.A. (1987). Model for combined effect of temperature and salt concentration /water activity on the growth rate of Staphylococcus xylosus. J. Appl. Bacteriol. 62: 543-550.

McNab, W.B. (1998). A general framework illustrating an approach to quantitative microbial food safety risk assessment. Journal of Food Protection. 61:1216-1228.

Monod, J. (1949). The growth of bacterial cultures. Ann. Rev. Microbiol. 3: 371-394.

Muñoz-Cuevas, M., Metris, A. and Baranyi, J. (2011). Predictive modelling of Salmonella: From cell cycle measurements to e-models, Food Research International. doi:10.1016/j.foodres.2011.04.033
Ratkowsky, D., Ross, T., McMeekin, T.A. and Olley, J. (1996), Comparison of Arrheniustype and Belehradek-type models for the prediction of bacterial growth in foods. $J$. Appl. Bacteriol. 71: 452-9.

Ratkowsky, D.A., Ross, T., Macario, N., Dommett, T.W. and Kamperman, L. (1996), Choosing probability distributions for modeling generation time variability. J. Appl. Bacteriol. 80:131-7.

Ratkowsky, D.A. (1991). Predicting response times in predictive microbiology. Occasional paper. Tasmania, Australia: Research and Development Unit, Biometrics Section, Dept of Primary Industry, Fisheries and Energy.

Ratkowsky, D.A., Ross, T., McMeekin, T.A. and Olley, J. (1991). Comparison of Arrhenius type and Belehradek models for prediction of bacterial growth in foods. J. Appl. Bacteriol. 71: 452-459.

Roberts, T.A. and Jarvis, B. (1983). Predictive Modeling of Food Safety with particular reference to Clostridium botulinum in model cured meat systems, in TA Roberts and FA Skinner (Eds.) Food Microbiology: Advances and Prospects, Orlando, FL, Academic Press. Pp. 85-95.

Roberts, T.A., Gibson, A.M. and Robinson, A. (1981), Prediction of toxin production by Clostridium botulinum in pasteurised pork slurry. Journal of Food Technology 16: 33755.

Roberts, T.A. (1989). Combinations of antimicrobials and processing methods. Food Technol. 43: 156-163.

Rodriguez, A.C., Smerage, G.H., Teixeira, A. A. and Busta, F.F. (1988). Kinetic effect of lethal temperature on population dynamics of bacterial spores. Transaction of the American Society of Agricultural Engineers 31: 15941601.

Roels, J. A. and Kossen, N. W. F. (1978). On the modeling of microbial metabolism. Prog. Ind. Microbiol. 14: 95-203.

Ross, T. and McMeekin, T.A. (1994). Predictive Microbiology. Int. J. Food Microbiol. 23: 241264.

Ross, T. and McMeekin, T.A. (1995). Predictive microbiology and HACCP. In: Pearson, A.M. Dutson, T.R. (Eds.) HACCP in meat, poultry and fish processing. London: Blackie Academic and Professional. Pp. 330-53.

Ross, T.(1996). Indices for performance evaluation of predictive models in food microbiology. J. Appl Bacteriol. 81: 501-508.

Rosso, L., Lobry, J.R., Bajard, S. and Flandrois, J.P. (1995). Convenient Model to Describe the Combined Effects of Temperature and $\mathrm{pH}$ on 
Microbial Growth. Applied and Environmental Microbiology 61(2): 610-6.

Scott, W.J. (1936). The growth of microorganisms on ox muscle. I. The influence of water content of substrate on rate of growth at $-1{ }^{\circ} \mathrm{C}$. J. Counc. Sci. Ind. Res.(Aust). 9: 177-182.

Skinner, G.E. and Larkin, J.W. (1994). Mathematical modeling of microbial growth: a review. J. Food Safety 14: 175-217.

Stumbo, C.R., Prokit, K.S., Ramarkrishnan, T.V., Evans, D.A. and Franaas, F.J. (1983). CRC handbook of lethality guides for low acid canned foods. 1. Boca Raton (FL). CRC Press.

Vose, D.J. (1998). The application of quantitative risk assessment to microbial food safety. Journal of Food Protection 61: 640 648.

Walker, S.J., Archer, P. and Banks, J.G. (1990). Growth of Listeria monocytogenes at refrigeration temperatures. J. Appl. Bacteriol. 68: $157-62$.

Whiting, R.C. and Buchanan, R.L. (1993). A classification of models for predictive microbiology. Food Microbiol. 10: 175-177.
Whiting, R.C. and Buchanan, R.L.B. (1997). Predictive modeling. In: Doyle MP, Beuchat L.R., Montville, T.J. (Eds.) Food microbiology fundamentals and frontiers. Washington (DC). American Society for Microbiology (In Press). Pp. 728-39.

Whiting, R.C. (1995). Microbial modeling in foods. Crit. Rev. Food Sci. 35(6): 467-494.

Whiting, R.C. and Buchanan R.L. (1994). Microbial modeling. Food Technology 48(6):113-119.

Whiting, R.C. (1992). Letter to the editor. Food Microbiol. 9: 173-174.

Whiting, R.C. (1997). Microbial database building: what have we learned? Food Technol. 51: 82-87.

Whiting, R.C. and Cygnarowicz P. M. (1992) Model for quantifying bacterial growth. Food Microbiol. 9: 269-277.

Xiong, R., Xie, G., Edmondson, A.E. and Sheard, M.A. (1999). A mathematical model for bacterial inactivation. Int. J. Food Microbiol. 46: 45-55. 